\title{
Fabrication of Fiber Reinforced Plastics by Ultrasonic Welding
}

\author{
Andreas Gomer*(D), Wei Zou®D, Niels Grigat, Johannes Sackmann ${ }^{\mathbb{D}}$ \\ and Werner Karl Schomburg $\mathbb{D}$
}

Konstruktion und Entwicklung von Mikrosystemen (Kemikro), RWTH Aachen University, Campus-Boulevard 30, 52074 Aachen, Germany; Zou@KEmikro.rwth-aachen.de (W.Z.); nielstobias.grigat@rwth-aachen.de (N.G.); Sackmann@KEmikro.rwth-aachen.de (J.S.); Schomburg@KEmikro.rwth-aachen.de (W.K.S.)

* Correspondence: Gomer@KEmikro.rwth-aachen.de; Tel.: +49-241-80-28-450

Received: 27 July 2018; Accepted: 13 September 2018; Published: 17 September 2018

check for updates

\begin{abstract}
Ultrasonic fabrication of fiber reinforced plastics made from thermoplastic polymer films and carbon or glass fibers enables cycle times of a few seconds and requires investment costs of only some $10,000 €$. Besides this, the raw materials can be stored at room temperature. A fiber content of $33 \mathrm{vol} \%$ and a tensile strength of approximately $1.2 \mathrm{GPa}$ have been achieved by ultrasonic welding of nine layers of foils from polyamide, each $100 \mu \mathrm{m}$ in thickness, and eight layers of carbon fibers, each $100 \mu \mathrm{m}$ in thickness, in between. Besides unidirectional carbon fiber reinforced polymer composite (CFRP) samples, multi-directional CFRP plates, $116 \mathrm{~mm}, 64 \mathrm{~mm}$ and $1.2 \mathrm{~mm}$ in length, width and thickness respectively, were fabricated by processing three layers of carbon fiber canvas, each $300 \mu \mathrm{m}$ in thickness, and eight layers of polyamide foils, each $100 \mu \mathrm{m}$ in thickness. Furthermore, both the discontinuous and the continuous ultrasonic fabrication processes are described and the results are presented in this paper. Large-scale production still needs to be demonstrated.
\end{abstract}

Keywords: fiber reinforced plastics; carbon fibers; glass fibers; polymer matrix composites; thermoplastic resin; ultrasonic processing; fabrication of fiber reinforced plastics (FRP)

\section{Introduction}

The most popular composites are fiber reinforced plastics (FRP), in which there is fiber material like glass (GFRP) or carbon (CFRP) embedded into a matrix material made of thermoplastic or thermoset polymer. The tensile strength to density ratio of CFRP, which is typically approximately 1.2 to $1.6 \mathrm{GPa} /\left(\mathrm{g} \cdot \mathrm{cm}^{-3}\right)$, is more than four times higher than that of steel $[1,2]$. By replacing steel with CFRP, it is possible to reduce the components' weight by $70 \%$ without any loss of mechanical resilience [2]. Therefore CFRP is mainly used within lightweight applications such as airplanes and cars [3].

However, CFRP with a thermoset matrix cannot be melted and deformed after initial solidification, restricting repair and recycling. Furthermore, the fabrication process of CFRP consumes in total three to five times more energy than steel production, including the fabrication of carbon fiber material itself [4]. Finally, the major drawback of CFRP is its high material costs, which can reach up to more than 300 US $\$ / \mathrm{kg}$ depending on the field of application [3]. Concluding these effects, a part made of CFRP is in total approximately six times more expensive than its steel equivalent [1].

This paper described how CFRP has been produced by ultrasonic processing of thermoplastic foils and carbon fibers. The cycle time of this process is only a few seconds and the required investment costs are on the order of some 10,000 $€$. Because of the local heating of the material, ultrasonic processing is relatively low energy consuming and various thermoplastic polymers as well as various 
fiber materials can be processed $[5,6]$. Figure 1 describes schematically how CFRP has been fabricated by ultrasonic welding.

A layer of carbon fibers with a thickness of approximately $100 \mu \mathrm{m}$ was placed between two layers of polypropylene (PP), each $200 \mu \mathrm{m}$ in thickness. Afterwards, this stack of carbon fibers and polymer foils was positioned and fixed on the anvil and under the horn of an ultrasonic welding machine. During the so-called down stroke step, the horn was moved downward onto the sample (see Figure 1a). After the horn reached the surface of the sample, it was compressed (see Figure 1b). As soon as the force reached a certain predetermined trigger force, ultrasonic vibrations were generated for a predetermined welding time. As a consequence, friction heat was generated between the fibers and the polymer, melting the polymer and embedding the fibers into the molten polymer (see Figure 1c). After the welding time of $1.5 \mathrm{~s}$, ultrasonic vibrations and melting were stopped and the heat was conducted away into the horn and the anvil. As a result, the polymer was solidifying within $1 \mathrm{~s}$, the so-called holding time. During the holding time, the compressing pressure was retained (see Figure 1d). Finally, the horn was moved upward to its initial position and the ultrasonically fabricated CFRP sample was released (see Figure 1e). The overall process cycle time was in the order of $5 \mathrm{~s}$. Furthermore, the set parameters of the ultrasonic process are summarized as process A in Table 1.

a)

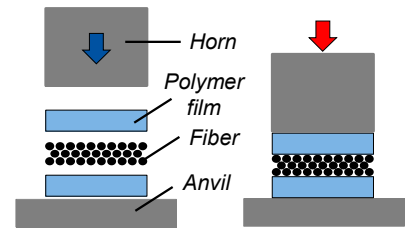

c) Ultrasonic

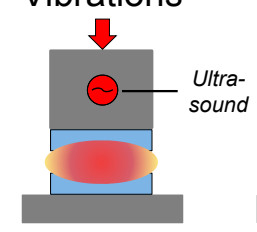

d)

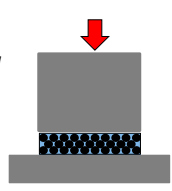

e)

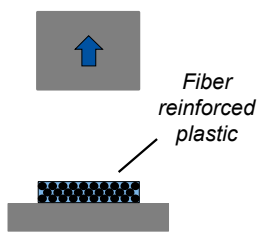

Figure 1. Schematic illustration of the ultrasonic fabrication of carbon fiber reinforced polymer composite (CFRP): (a) Carbon fibers placed between polymer layers on top of the anvil and under the horn of an ultrasonic welding machine. Down stroke of the horn; (b) Buildup of a mechanical force by the horn and compression of the sample; (c) Ultrasonic vibrations generate friction heat between fibers and polymer, melting the polymer and embedding the fibers; (d) De-activating ultrasonic vibrations and retaining force for solidification; (e) Demolding the ultrasonically fabricated sample from the machine.

Table 1. Overview of the process conditions and the parameters for the ultrasonic fabrication of CFRP with the Branson 2000IW+ Ultrasonic Welder.

\begin{tabular}{|c|c|c|c|c|c|}
\hline Process & $\begin{array}{l}\text { Welding } \\
\text { Force (N) }\end{array}$ & $\begin{array}{c}\text { Trigger } \\
\text { Force (N) }\end{array}$ & $\begin{array}{l}\text { Welding } \\
\text { Time (s) }\end{array}$ & $\begin{array}{l}\text { Holding } \\
\text { Time (s) }\end{array}$ & $\begin{array}{c}\text { Ultrasonic } \\
\text { Amplitude }(\mu \mathrm{m})\end{array}$ \\
\hline $\begin{array}{l}\text { A: } 1 \text { layer of carbon fibers, } 100 \mu \mathrm{m} \text { in thickness, } \\
\text { and } 2 \text { layers of PP foils, each } 200 \mu \mathrm{m} \text {. }\end{array}$ & 3200 & 220 & 1.5 & 1.0 & 32.0 \\
\hline $\begin{array}{l}\text { L: } 3 \text { layers of carbon fibers, each } 100 \mu \mathrm{m} \text { in } \\
\text { thickness, and } 4 \text { layers of PA foils, each } 200 \mu \mathrm{m} \text {. }\end{array}$ & 1800 & 870 & 1.5 & 1.0 & 30.4 \\
\hline
\end{tabular}

In an initial experiment, the prior described ultrasonic fabrication process was used to fabricate CFRP samples, which consisted of one layer of carbon fibers embedded into a PP matrix. Figure 2 displays one example of an ultrasonically fabricated CFRP sample. After the fabrication process, the samples were trimmed to the dimensions of approximately $10 \mathrm{~mm}$ in width and $25 \mathrm{~mm}$ to $30 \mathrm{~mm}$ in length. The thickness of the samples was approximately $470 \mu \mathrm{m}$. To demonstrate that all fibers were embedded fully into the PP matrix, the upper matrix layer and some fibers were cut off and removed partly. Because a unidirectional carbon fiber roving was employed as raw material, all the fibers of the fabricated CFRP sample were orientated unidirectional as well. 


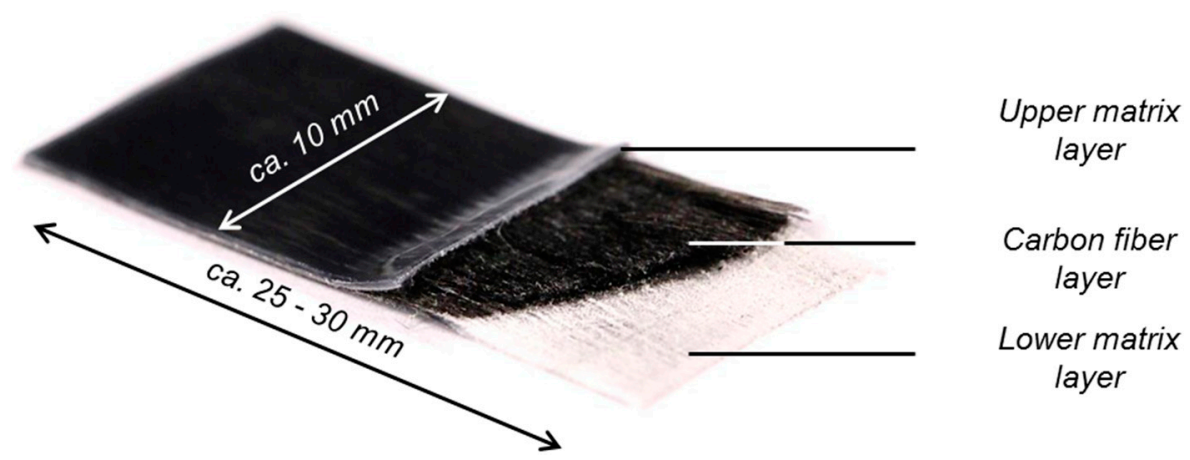

Figure 2. Ultrasonically fabricated CFRP made of carbon fibers between two layers of polypropylene (PP). The thickness of the sample was approximately $470 \mu \mathrm{m}$. To demonstrate that the fibers were embedded fully, the upper matrix layer was cut off and removed partly.

Ultrasonic energy generated within the ultrasonic welding process has been used in industrial applications such as welding, deforming and joining of thermoplastic polymer materials for more than six decades [5,6]. However, in the field of composite materials, ongoing research activities focus on employing the ultrasonic welding process for the joining of CFRP parts, which were fabricated by industrial state of the art fabrication processes such as pultrusion, winding, processing of prepregs or resin transfer moulding (RTM). Furthermore, CFRP parts joined by ultrasonic welding can be made from both a thermoplastic and a thermoset matrix material [7-12].

Besides the joining of already fabricated CFRP, it was demonstrated that the ultrasonic welding process can also be used for the initial fabrication of CFRP itself made from prepregs, tapes or preforms [13-18]. Furthermore, it is possible to use ultrasonic welding to process the so-called pseudo-prepregs made of continuously commingled glass fibers and PP filaments, which allows to fabricate GFRP within a roll-to-roll process $[19,20]$.

However, these approaches still require semi-finished CFRP products as raw materials, which need to be fabricated within a prior processing step. On the contrary, the approach presented in this paper avoids using semi-finished CFRP and employs dry carbon fibers from fiber rovings and rolls of solid thermoplastic polymer film with various thicknesses as raw materials. Both materials are processed in just one continuous processing step within seconds to finished CFRP by ultrasonic welding. Furthermore, the materials can be stored at room temperature for an unlimited time.

Based on the promising results of the first experiment, further research activities dealt with the systematic development of the ultrasonic fabrication process of CFRP. During the development process, the amount of fiber layers within the fabricated CFRP-samples was increased successively. Furthermore, not only carbon fibers but also glass fibers and carbon fiber canvas as well as various thermoplastic matrix materials were employed as raw process materials. Besides the discontinuous processing, the continuous ultrasonic fabrication of CFRP was demonstrated as well. Finally, material properties of the CFRP such as fiber volume content and tensile strength were examined and summarized.

\section{Materials and Methods}

\subsection{Machines}

During the development of ultrasonic fabrication of FRP three different ultrasonic welding machines were used. These machines are introduced in this section. Furthermore, their main processing characteristics such as ultrasonic frequency, maximum ultrasonic amplitude, dimensions of the ultrasonic horn, maximum pressing force and maximum power are named.

The Branson 2000IW+ Ultrasonic Welder from Emerson Electric Inc., St. Louis, MO, USA works at an ultrasonic frequency of $20 \mathrm{kHz}$. Maximum ultrasonic amplitude, power and pressing force are $32 \mu \mathrm{m}$, $2.2 \mathrm{~kW}$ and $3.2 \mathrm{kN}$, respectively [21]. The dimensions of the horn are $60 \mathrm{~mm} \times 40 \mathrm{~mm}$. This ultrasonic 
welding machine was employed for processes A and L presented in this paper. Table 1 summarizes the set processing parameters.

The Herrmann Ultraschall HiQ DIALOG 1200 ultrasonic welding machine from Herrmann Ultraschalltechnik GmbH \& Co. KG, Karlsbad, Germany works at $35 \mathrm{kHz}$. Maximum ultrasonic amplitude, power and pressing force are $31 \mu \mathrm{m}, 1.2 \mathrm{~kW}$ and $650 \mathrm{~N}$, respectively [22]. The dimensions of the horn are $60 \mathrm{~mm} \times 40 \mathrm{~mm}$. This machine was employed for process B. Table 2 summarizes the set processing parameters.

Table 2. Overview of the process conditions and the parameters for the ultrasonic fabrication of CFRP with the Herrmann Ultraschall HiQ DIALOG 1200 ultrasonic welding machine.

\begin{tabular}{|c|c|c|c|c|c|}
\hline Process & $\begin{array}{l}\text { Welding } \\
\text { Force (N) }\end{array}$ & $\begin{array}{c}\text { Trigger } \\
\text { Force (N) }\end{array}$ & $\begin{array}{l}\text { Welding } \\
\text { Time (s) }\end{array}$ & $\begin{array}{l}\text { Holding } \\
\text { Time (s) }\end{array}$ & $\begin{array}{c}\text { Ultrasonic } \\
\text { Amplitude }(\mu \mathrm{m})\end{array}$ \\
\hline $\begin{array}{l}\text { B: } 6 \text { layers of carbon fibers, each } 100 \mu \mathrm{m} \text { in } \\
\text { thickness, and } 7 \text { layers of PP foils, each } 200 \mu \mathrm{m} \text {. }\end{array}$ & 500 & 600 & 0.65 & 2.0 & 30.0 \\
\hline
\end{tabular}

The Herrmann Ultraschall HiQ DIALOG 6200 ultrasonic welding machine from Herrmann Ultraschalltechnik GmbH \& Co. KG, Karlsbad, Germany works at $20 \mathrm{kHz}$. Maximum ultrasonic amplitude, power and pressing force are $30.6 \mu \mathrm{m}, 6.2 \mathrm{~kW}$ and $2.49 \mathrm{kN}$, respectively [22]. The dimensions of the horn are $120 \mathrm{~mm} \times 80 \mathrm{~mm}$. This machine was employed for processes $\mathrm{C}$, $\mathrm{D}, \mathrm{E}, \mathrm{F}, \mathrm{G}, \mathrm{H}, \mathrm{M}$ and $\mathrm{N}$. Table 3 summarizes the set processing parameters. When two welding forces are named, there was a raise of force during the ultrasonic welding process.

Table 3. Overview of the process conditions and the parameters for the ultrasonic fabrication of CFRP with the Herrmann Ultraschall HiQ DIALOG 6200 ultrasonic welding machine.

\begin{tabular}{|c|c|c|c|c|c|}
\hline Process & $\begin{array}{l}\text { Welding } \\
\text { Force (N) }\end{array}$ & $\begin{array}{c}\text { Trigger } \\
\text { Force }(\mathrm{N})\end{array}$ & $\begin{array}{l}\text { Welding } \\
\text { Time (s) }\end{array}$ & $\begin{array}{l}\text { Holding } \\
\text { Time (s) }\end{array}$ & $\begin{array}{c}\text { Ultrasonic } \\
\text { Amplitude }(\mu \mathrm{m})\end{array}$ \\
\hline $\begin{array}{l}\text { C: } 8 \text { layers of carbon fibers, each } 100 \mu \mathrm{m} \text { in } \\
\text { thickness, and } 9 \text { layers of PA foils, each } 100 \mu \mathrm{m} .\end{array}$ & $500 / 2000$ & 500 & 3.0 & 5.0 & 22.0 \\
\hline $\begin{array}{l}\text { D: } 17 \text { layers of carbon fibers, each } 100 \mu \mathrm{m} \text { in } \\
\text { thickness, and } 18 \text { layers of PA foils, each } 100 \mu \mathrm{m} \text {. }\end{array}$ & $1200 / 2000$ & 1200 & 15.0 & 5.0 & 30.0 \\
\hline $\begin{array}{l}\text { E: } 4 \text { layers of carbon fibers, each } 100 \mu \mathrm{m} \text { in } \\
\text { thickness, and } 5 \text { layers of PA foils, each } 100 \mu \mathrm{m} .\end{array}$ & $500 / 2000$ & 500 & 4.0 & 5.0 & 30.0 \\
\hline F: 5 layers of CFRP made within process $\mathrm{E}$ & $500 / 2000$ & 500 & 6.0 & 5.0 & 20.0 \\
\hline $\begin{array}{l}\text { G: } 4 \text { layers of glass fibers, each } 200 \mu \mathrm{m} \text { in } \\
\text { thickness, and } 5 \text { layers of PA foils, each } 100 \mu \mathrm{m} \text {. }\end{array}$ & 2000 & 500 & 4.5 & 5.0 & 30.0 \\
\hline $\begin{array}{l}\text { H: } 3 \text { layers of canvas, each } 300 \mu \mathrm{m} \text { in thickness, } \\
\text { and } 8 \text { layers of PA foils, each } 100 \mu \mathrm{m} .\end{array}$ & $500 / 2000$ & 500 & 16.0 & 5.0 & 30.6 \\
\hline
\end{tabular}

The CERA 100 ultrasonic welding machine from CERA Engineering SAS, Villars, France works at $35 \mathrm{kHz}$. Maximum ultrasonic amplitude, power and piston pressure are $20 \mu \mathrm{m}, 1 \mathrm{~kW}$ and $0.5 \mathrm{MPa}$, respectively [23]. The width of the disk-shaped horn was $8 \mathrm{~mm}$. This machine was employed for processes I, J and $\mathrm{K}$. Table 4 summarizes the set processing parameters. 
Table 4. Overview of the process conditions and the parameters for the ultrasonic fabrication of CFRP by the CERA 100 ultrasonic welding machine.

\begin{tabular}{lccc}
\hline \multicolumn{1}{c}{ Process } & $\begin{array}{c}\text { Piston Pressure } \\
(\mathbf{M P a})\end{array}$ & $\begin{array}{c}\text { Feed } \\
(\mathrm{m} / \mathrm{min})\end{array}$ & $\begin{array}{c}\text { Ultrasonic Amplitude } \\
(\mu \mathrm{m})\end{array}$ \\
\hline $\begin{array}{l}\text { I: } 3 \text { layers of carbon fibers, each } 50 \mu \mathrm{m} \text { in thickness, and } 4 \\
\text { layers of PE foils, each 150 } \mu \mathrm{m} \text { in thickness. }\end{array}$ & 0.5 & 4.0 & 20 \\
\hline $\begin{array}{l}\text { J: } 2 \text { layers of carbon fibers, each } 50 \mu \mathrm{m} \text { in thickness, and } 3 \\
\text { layers of PA foils, each 100 } \mu \mathrm{m} \text { in thickness. }\end{array}$ & 0.4 & 4.0 & 17.5 \\
\hline $\begin{array}{l}\text { K: } 1 \text { layer of carbon fibers, } 50 \mu \mathrm{m} \text { in thickness, and 2 layers } \\
\text { of PP foils, each 200 } \mu \mathrm{m} \text { in thickness. }\end{array}$ & 0.3 & 4.0 & 20 \\
\hline
\end{tabular}

During the ultrasonic fabrication of CFRP, the carbon fiber and the polymer film layers had to be positioned and fixed on the anvil and under the horn of the ultrasonic welding machine. Therefore, strips of an adhesive tape and a self-constructed clamping tool were used. Figure 3 illustrates the fixing process.

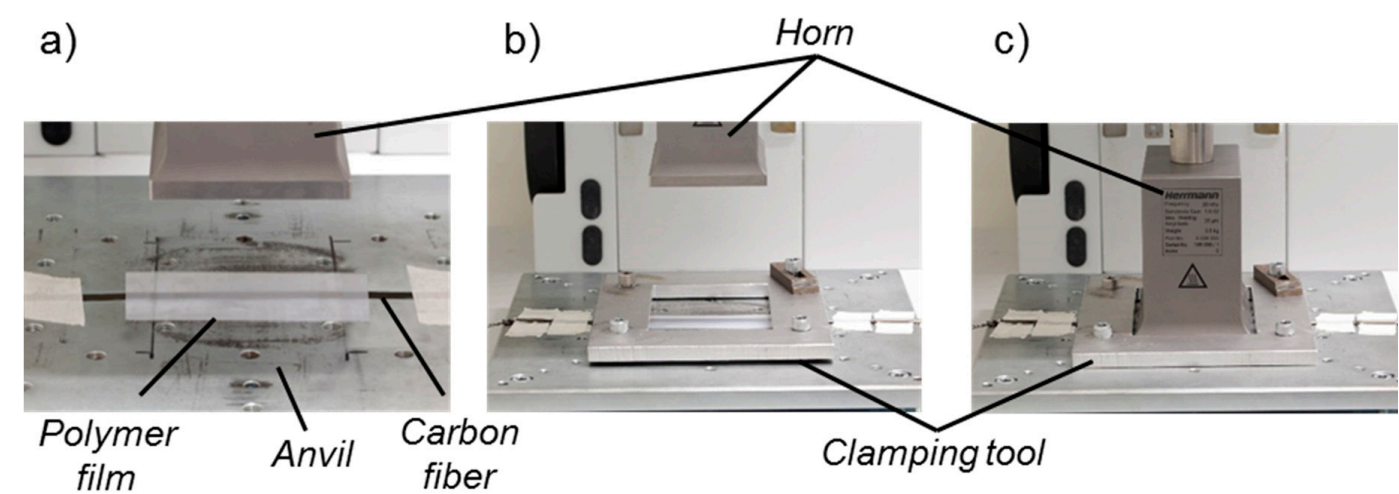

Figure 3. Positioning and fixing of the carbon fiber layers and the layers the polymer film on the anvil and under the horn of the Herrmann Ultraschall HiQ DIALOG 6200 ultrasonic welding machine. (a) Placing and stacking of the carbon fibers and the polymer film layers on the anvil; (b) fixing the stack of carbon fibers and the polymer film layers in their position with a clamping tool; (c) activating the ultrasonic welding process to fabricate carbon fiber reinforced plastics (CFRP).

First the layers of carbon fibers and polymer film were stacked and placed on the anvil (see Figure 3a). Adhesive tape was used to fix the stack of carbon fibers and polymer film preliminary. Because of the limited mechanical force from the adhesive tapes of approximately less than $10 \mathrm{~N}$, a clamping tool was necessary to build up a higher mechanical force fixing the fibers in their position. The clamping tool was placed on the anvil of the ultrasonic welding machine, but the screws had not been tightened yet (see Figure 3b).

Afterwards, the horn of the ultrasonic welding machine was moved downward and built up a mechanical force. Finally, the screws of the clamping tool were tightened and therefore the fibers and polymer film layers were fixed in their position (see Figure 3c). The ultrasonic horn was moved upward to its initial position. After this fixing step, the ultrasonic welding process begun and the CFRP sample was fabricated.

As processing parameters of the ultrasonic welding process cannot be predicted in advance precisely [6], they had to be determined through trial and error experiments for every setup individually, with respect to the materials used and their dimensions as well as the amount of fiber and polymer film layers. Therefore, a batch of samples was produced initially to determine suitable processing parameters for various setups. Using suitable processing parameters, which were chosen based on criteria such as uniformity of welding and full embedding of the fibers, a batch of testing samples with various amounts of CFRP samples was produced afterwards. For each setup the exact amount of the batch size is named in Section 3.5. 
According to the dimension of the ultrasonic horn used in the fabrication process, the samples were approximately $60 \mathrm{~mm}$ to $80 \mathrm{~mm}$ in length. The width of the inhomogeneous samples was $50 \mathrm{~mm}$, which consisted of approximately $10 \mathrm{~mm}$ to $15 \mathrm{~mm}$ of embedded fibers and the rest of unfilled polymer material. To fabricate homogeneous CFRP samples and to compare the results of the tensile tests in Section 3, all the samples needed to be trimmed to same dimensions. Based on the sample's center point in width and length after initial fabrication, they were trimmed to $8 \mathrm{~mm}$ and $55 \mathrm{~mm}$ in width and length, respectively. The height of the sample was a function of the amount of carbon fibers and polymer film layers used. Those dimensions were measured for every sample individually by an optical microscope. Furthermore, every sample was weighed by a micro scale. This information was used to calculate the cross-section area of the sample and later to determine the tensile strength applied on a sample. From each batch of testing samples, every ultrasonically fabricated CFRP samples was prepared and tested within tensile tests.

To measure the tensile strength of the CFRP samples, the zwickiLine Materials Testing Machine Z5.0 tensile strength testing machine from Zwick GmbH \& Co. KG, Ulm, Germany, was used. The maximum test load in tensile direction of the machine was $5 \mathrm{kN}$ and the crosshead speed can be set from $0.0005 \mathrm{~mm} / \mathrm{min}$ up to $600 \mathrm{~mm} / \mathrm{min}$ [24]. The force measurement accuracy fulfills the requirements of the grade 0.5 according to DIN EN ISO 7500-1 and ASTM E4, what means that the measuring error of the machine is less than $0.5 \%$ [24].

For the measurement of the tensile strength, the CFRP-sample was placed and fixed in the clamping claws of the tensile testing machine. Both clamping claws were tightened with a torque of $14 \mathrm{~N} \cdot \mathrm{m}$. The distance between both clamping claws was set to $15 \mathrm{~mm}$. The testing velocity was set to $1 \mathrm{~mm} / \mathrm{min}$. During the test, the tensile force was measured and later used to calculate the tensile strength together with the cross-section of every sample individually.

\subsection{Materials}

For the development of the ultrasonic fabrication of FRP various polymer matrix materials as well as fiber materials were examined. Those materials, their relevant mechanical properties as well as the supplying company are introduced within this section.

The Tecfilm PP TC 00170 polypropylene (PP) foil used in this paper was supplied in various thicknesses by Dr. Dietrich Müller $\mathrm{GmbH}$, Ahlhorn, Germany. The density of the PP foil was $0.9 \mathrm{~g} \cdot \mathrm{cm}^{-3}$, the maximum tensile strength was $80 \mathrm{MPa}$ and the elongation at break was approximately $150 \%$ [25].

The Nowocast HD polyethylene (PE) foil was supplied by Nowofol Kunststoffprodukte GmbH \& Co. KG, Siegsdorf, Germany. The density, maximum tensile strength and elongation at break of the PE foil were $0.945 \mathrm{~g} \cdot \mathrm{cm}^{-3}, 20 \mathrm{MPa}$ and up to $600 \%$, respectively [26].

The Cast Nylon Film PA 6 polyamide 6 (PA6) foil was supplied in various thicknesses by mf-folien $\mathrm{GmbH}$, Kempten, Germany. Density, maximum tensile strength and elongation at break of this foil were $1.14 \mathrm{~g} \cdot \mathrm{cm}^{-3}, 80 \mathrm{MPa}$ and up to $400 \%$, respectively [27].

The carbon fiber Tenax-HTS40 F13 12K 800tex was supplied by Toho Tenax GmbH, Heinsberg, Gemany. One layer of the fibers had a thickness of approximately $100 \mu \mathrm{m}$ and a width of approximately $8 \mathrm{~mm}$. Density, maximum tensile strength and elongation at break of the carbon fibers were $1.77 \mathrm{~g} \cdot \mathrm{cm}^{-3}$, $4.4 \mathrm{GPa}$ and up to $1.8 \%$, respectively [28].

The glass fiber E-CR1200 was supplied by Mühlmeier GmbH \& Co. KG, Bärnau, Gemany [29]. One layer of the fibers had a thickness of approximately $100 \mu \mathrm{m}$ and a width of approximately $7 \mathrm{~mm}$. Further information on the mechanical properties were not available but also not needed, because no mechanical tensile tests were performed with the GFRP sample. Figure 4 shows the polymer matrix as well as the fiber materials used in this paper. 

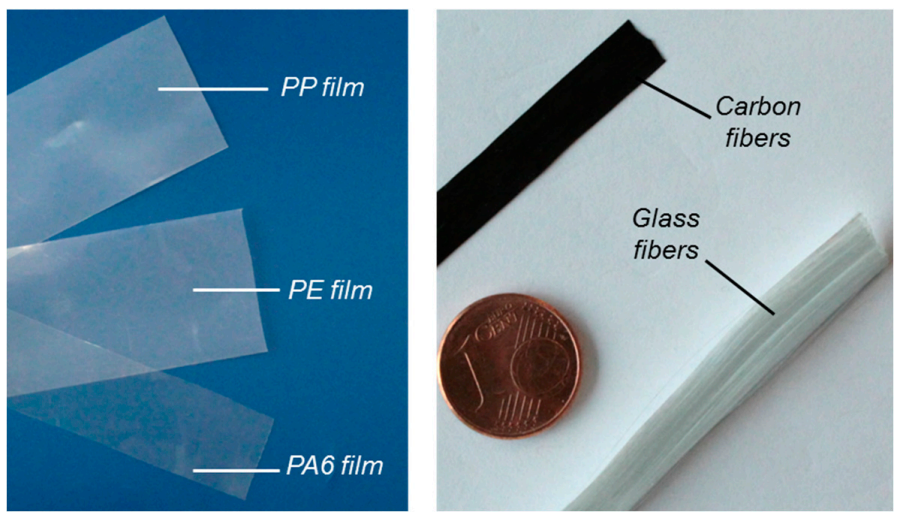

Figure 4. Overview of the polymer foils and fiber materials used in this paper.

\subsection{Methods}

The fiber volume content $\phi_{C}$ of the ultrasonically fabricated CFRP was calculated from the conservation of mass and the densities $\rho$ and volumes $\mathrm{V}$ of CFRP, fibers and matrix polymer:

$$
\mathrm{m}_{\mathrm{C}}=\mathrm{m}_{\mathrm{f}}+\mathrm{m}_{\mathrm{m}}=\rho_{\mathrm{f}} \mathrm{V}_{\mathrm{f}}+\rho_{\mathrm{m}} \mathrm{V}_{\mathrm{m}}=\rho_{\mathrm{C}} \mathrm{V}_{\mathrm{C}}=\rho_{\mathrm{f}} \varphi_{\mathrm{f}} \mathrm{V}_{\mathrm{C}}+\rho_{\mathrm{m}} \varphi_{\mathrm{m}} \mathrm{V}_{\mathrm{C}}
$$

where the indexes $\mathrm{C}, \mathrm{f}$ and $\mathrm{m}$ denote $\mathrm{CFRP}$, fibers and matrix polymer and $\varphi$ denotes the fiber or matrix content, respectively. Dividing the last two parts of the above equation by $\mathrm{V}_{\mathrm{C}}$ yields:

$$
\rho_{\mathrm{C}}=\rho_{\mathrm{f}} \varphi_{\mathrm{f}}+\rho_{\mathrm{m}} \varphi_{\mathrm{m}}=\rho_{\mathrm{f}} \varphi_{\mathrm{f}}+\rho_{\mathrm{m}}\left(1-\varphi_{\mathrm{f}}\right) \rightarrow \varphi_{\mathrm{f}}=\frac{\rho_{\mathrm{C}}-\rho_{\mathrm{m}}}{\rho_{\mathrm{f}}-\rho_{\mathrm{m}}}
$$

The density of the ultrasonically fabricated CFRP sample was calculated by weighting and measuring the geometrical dimension of every sample. The density of fiber and matrix material were taken from their technical data sheet (see Section 2.2).

\section{Results}

\subsection{Ultrasonic Fabrication of Multi Layered CFRP}

Based on achieved results of the initial experiment, in further experiments thicker CFRP plates were fabricated by ultrasonic welding of several layers for fibers and foils in a single step (see Figure 5).

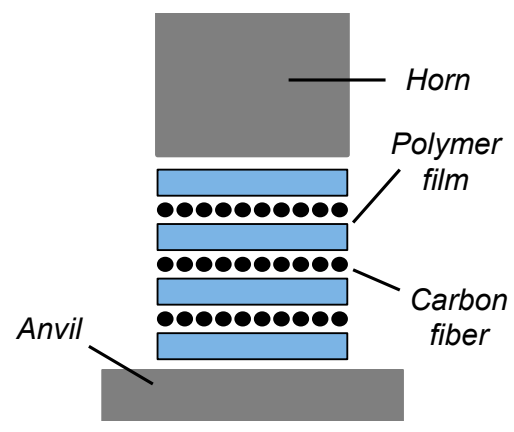

Figure 5. Schematic illustration of the ultrasonic fabrication of multi layered CFRP.

Up to six layers of carbon fibers, each $100 \mu \mathrm{m}$ in thickness, and seven layers of PP foils, each $200 \mu \mathrm{m}$ in thickness, were welded together in a single welding process. The total thickness of the fabricated samples was approximately $1.8 \mathrm{~mm}$ and all fibers were orientated in one direction because unidirectional carbon fibers were used as a raw material. All the fibers were embedded fully 
into the various layers of molten polymer matrix material. The process parameters are summarized as process B in Table 2. Figure 6 illustrates a microscopic view of a cut through the CFRP in fiber direction.

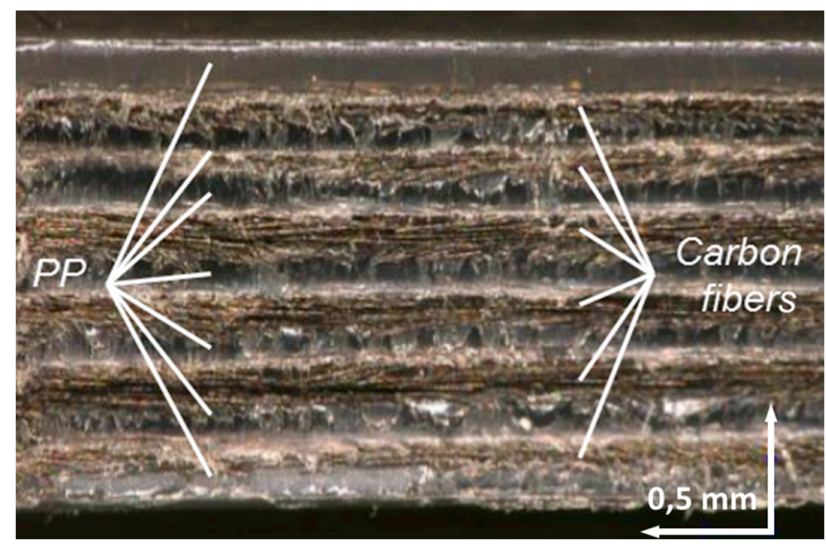

Figure 6. Microscopic view on a cut in direction of the fibers through a CFRP sample with a total thickness of approximately $1.8 \mathrm{~mm}$ made of six layers of carbon fibers and seven layers of PP-foils.

Although all the fibers were embedded completely, the CFRP sample was inhomogeneous because separate layers of polymer and carbon fibers are seen on a cut (cf. Figure 6). Especially the upmost PP layer had still a thickness of approximately $150 \mu \mathrm{m}$ after welding. This means that the total amount of PP used within process B was larger than necessary for embedding the fibers completely.

In further experiments polyamide (PA) films were employed as matrix material. As shown in Figure 6, several PA foils were positioned between the anvil and the horn of the ultrasonic welding machine and ultrasonically welded to CFRP. By using nine PA foils, each $100 \mu \mathrm{m}$ in thickness, the amount of matrix material in the CFRP sample was reduced. The trigger force was set to $500 \mathrm{~N}$ and the welding force was raised from $500 \mathrm{~N}$ to $2 \mathrm{kN}$ in $0.5 \mathrm{~s}$. The parameters are summarized as process $\mathrm{C}$ in Table 3. This way, a homogeneous cross-section of the CFRP was achieved (see Figure 7). The thickness of the sample was approximately $900 \mu \mathrm{m}$ in total.

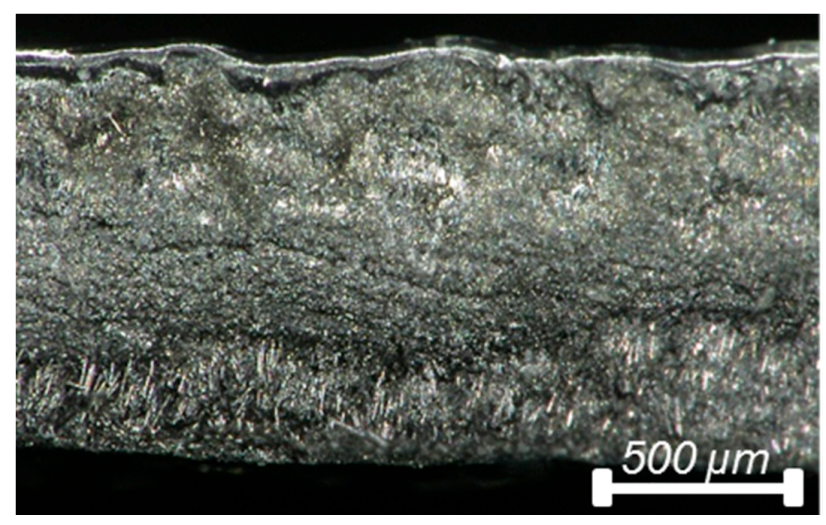

Figure 7. Microscopic view on a cut orthogonal to the direction of the fibers through a CFRP sample fabricated by process $C$ from eight layers of carbon fibers and nine layers of PA foils, all $100 \mu \mathrm{m}$ in thickness, resulting in $900 \mu \mathrm{m}$ total thickness of the CFRP.

In further experiments up to 17 layers of carbon fibers and 18 layers of PA film, all $100 \mu \mathrm{m}$ in thickness, were welded in a single process to CFRP. Figure 8 displays such a sample. The parameters are summarized as process D in Table 2.

The width of the samples expanded from $8 \mathrm{~mm}$ before welding to up to approximately $15 \mathrm{~mm}$ after welding. The total thickness of the sample was approximately $1 \mathrm{~mm}$. It appears to be possible to reduce this extension by applying a preliminary tension on the fibers. 


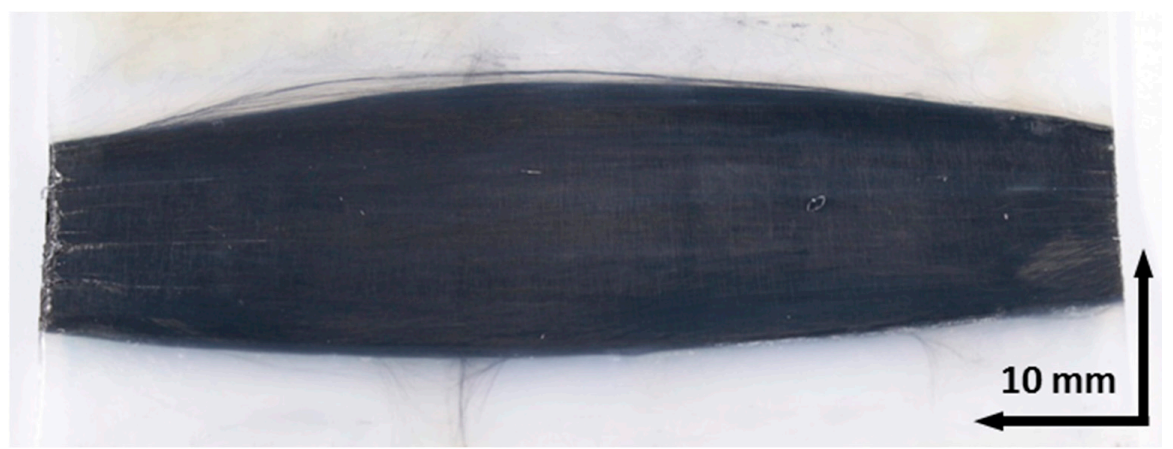

Figure 8. Ultrasonically fabricated CFRP sample made from 17 layers of carbon fibers and 18 layers of PA foils, all $100 \mu \mathrm{m}$ in thickness. The total thickness of the CFRP was $1 \mathrm{~mm}$.

Up to 20 layers of carbon fibers were welded into a PA matrix by first fabricating five CFRPs with four layers of carbon fibers embedded in five layers of PA and then joining these five CFRPs without any additional fibers by ultrasonic welding. The processing parameters of this process $\mathrm{E}$ and $\mathrm{F}$ are summarized in Table 3.

Besides the ultrasonic fabrication of unidirectional CFRP it was also demonstrated to fabricate multi-directional CFRP. Various layers of unidirectional carbon fibers were placed at different orientations between the polymer layers. The first carbon fiber layer was orientated at $0^{\circ}$ direction, the second was orientated orthogonally to the first one at $90^{\circ}$ direction and the third layer in $\pm 45^{\circ}$ direction, and so on. This procedure allowed for ultrasonically fabricating quasi-isotropic CFRP from unidirectional carbon fiber rovings.

\subsection{Ultrasonic Fabrication of GFRP}

Glass fiber reinforced plastics (GFRP) have already been made by ultrasonic fabrication from pseudo-prepregs made of continuous commingled glass fibers and PP filaments [19]. However, the approach presented in this paper showed that it is also possible to employ polymer films with various thicknesses instead of PP filaments. GFRP were fabricated similarly as CFRP by ultrasonic processing (cf. process $\mathrm{G}$ in Table 3). Figure 9 displays a GFRP sample, made from four layers of glass fibers, with a thickness of approximately $200 \mu \mathrm{m}$ each, and five layers of PA film with a thickness of $100 \mu \mathrm{m}$ each. The GFRP sample had a total thickness of approximately $900 \mu \mathrm{m}$.

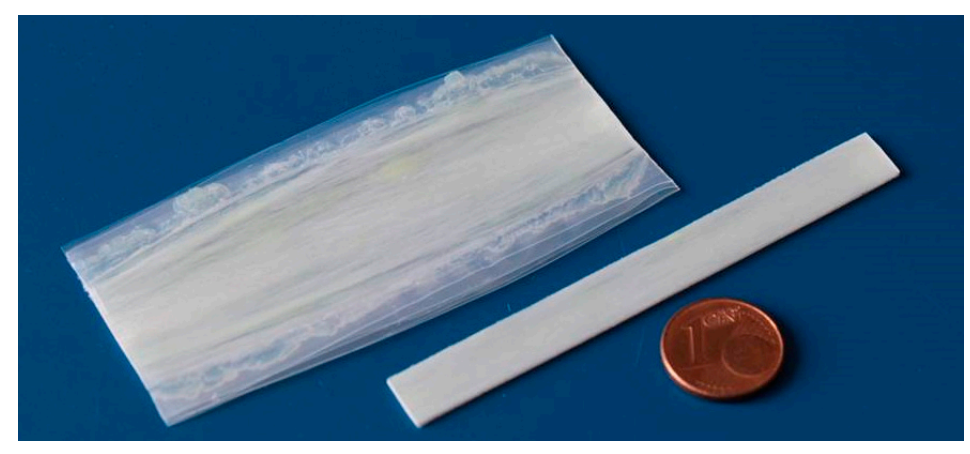

Figure 9. Ultrasonically fabricated GFRP made from four layers of glass fiber roving with a thickness of $200 \mu \mathrm{m}$ each and five layers of PA film with a thickness of $100 \mu \mathrm{m}$ each.

\subsection{Ultrasonic Fabrication of CFRP-Plates}

Besides processing unidirectional fibers, the ultrasonic fabrication also allowed to process carbon fiber canvas, which consisted of carbon fibers woven into a $0^{\circ}$ and $90^{\circ}$ mash [30] (see left side of Figure 10). The yellow marked area shows the welding area of the horn. To fabricate CFRP plates, three layers of carbon fiber canvas with a thickness of $300 \mu \mathrm{m}$ each were placed between eight PA foils, 
each $100 \mu \mathrm{m}$ in thickness, and ultrasonically welded. The processing parameters of the process $\mathrm{H}$ are summarized in Table 3.
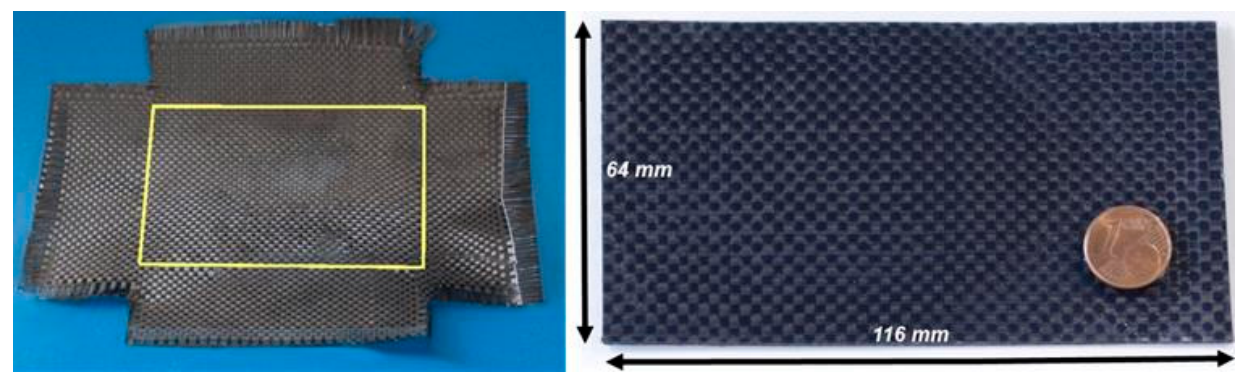

Figure 10. Raw carbon fiber canvas with marked welding area (left). Ultrasonically fabricated CFRP plate from three layers of carbon fiber canvas with a thickness of $300 \mu \mathrm{m}$ each and eight layers of PA film, each $100 \mu \mathrm{m}$ in thickness. The fabricated CFRP plate had outer dimensions $116 \mathrm{~mm} \times 64 \mathrm{~mm}$ and the thickness was $1.2 \mathrm{~mm}$.

The right side of Figure 10 shows the CFRP plate after it was ultrasonically fabricated and trimmed. This plate was approximately $116 \mathrm{~mm}$ in length, $61 \mathrm{~mm}$ in width and had a thickness of approximately $1.2 \mathrm{~mm}$. The dimensions of the fabricated plate were limited to the dimensions of the ultrasonic horn.

\subsection{Continuous Ultrasonic Fabrication of CFRP}

Besides the discontinuous fabrication process of CFRP described in Section 1, a continuous process was investigated as well. An ultrasonic welding machine consisting of a disk-shaped rotating horn and anvil was employed. The left side of Figure 11 illustrates the working principle of the continuous ultrasonic fabrication of CFRP. Similar to the discontinuous process, the stack of carbon fibers and polymer film was placed between the horn and the anvil. Both the horn and the anvil are rotating during ultrasonic welding, transporting the sample.
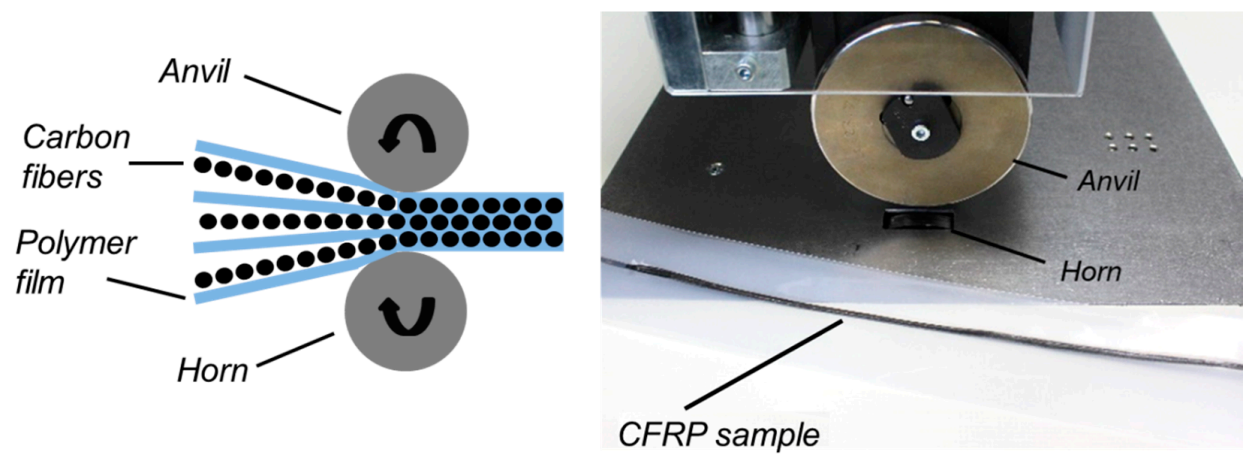

Figure 11. Schematic illustration of the working principle of continuous ultrasonic fabrication of CFRP (left). Ultrasonically fabricated CFRP sample with a length of $30 \mathrm{~cm}$ made from three layers of carbon fibers, each $50 \mu \mathrm{m}$ in thickness, and four layers of PE foils, each $150 \mu \mathrm{m}$ in thickness (right).

Figure 11 shows the experimental setup for the continuous ultrasonic fabrication of CFRP as well as the fabricated sample. The experiments showed that with process I, it is possible to fabricate samples from four layers of PE foils, each $150 \mu \mathrm{m}$ in thickness, and three layers of carbon fibers, each $50 \mu \mathrm{m}$ in thickness, with a total length of up to $30 \mathrm{~cm}$. Furthermore, additional investigations focused on the variation of the polymer material employed as well as the amount of carbon fiber layers within the fabricated CFRP sample. For instance, in process J, two layers of carbon fibers with a thickness of $50 \mu \mathrm{m}$ each and three layers of PA foil with a thickness of $100 \mu \mathrm{m}$ each were processed to CFRP. Finally, in process $\mathrm{K}$ one layer of carbon fiber with a thickness of $50 \mu \mathrm{m}$ and two layers of PP foils 
with a thickness of $200 \mu \mathrm{m}$ each were processed. The processing parameters of processes I, J and $\mathrm{K}$ are summarized in Table 4.

\subsection{Mechanical Testing}

Besides the examination of the fabrication process, the mechanical properties of the fabricated CFRP were investigated. Samples with different amounts of carbon fiber layers as well as polymer film layers were fabricated. The manufactured batch consisted of CFRP samples with three, four, five and eight layers of carbon fibers. PA was used as matrix material. The process parameters for processes $\mathrm{E}$, $\mathrm{L}, \mathrm{M}$ and $\mathrm{N}$ are summarized in Tables 1 and 3. After ultrasonic fabrication of the CFRP, the samples were trimmed, weighed and their dimensions were measured according to the method described in Section 2.1. Afterwards, tensile tests were performed, the tensile force of breakage was determined and finally the tensile strength of the samples was calculated. The following Table 5 summarizes the results of the tensile test.

Table 5. Mean tensile strength and standard deviation of the ultrasonically fabricated CFRP samples measured within tensile tests.

\begin{tabular}{|c|c|c|c|}
\hline Process & $\begin{array}{l}\text { Mean Tensile } \\
\text { Strength (MPa) }\end{array}$ & $\begin{array}{c}\text { Standard } \\
\text { Deviation }(\%)\end{array}$ & $\begin{array}{l}\text { Samples } \\
\text { Tested (-) }\end{array}$ \\
\hline $\begin{array}{l}\text { L: } 3 \text { layers of carbon fibers, each } 100 \mu \mathrm{m} \text { in thickness, and } \\
4 \text { layers of PA foils, each } 200 \mu \mathrm{m} .\end{array}$ & $502 \pm 42$ & 8.4 & 5 \\
\hline $\begin{array}{l}\text { E: } 4 \text { layers of carbon fibers, each } 100 \mu \mathrm{m} \text { in thickness, and } \\
5 \text { layers of PA foils, each } 100 \mu \mathrm{m} \text {. }\end{array}$ & $819 \pm 113$ & 13.8 & 17 \\
\hline $\begin{array}{l}\text { M: } 5 \text { layers of carbon fibers, each } 100 \mu \mathrm{m} \text { in thickness, and } \\
6 \text { layers of PA foils, each } 100 \mu \mathrm{m} .\end{array}$ & $1001 \pm 142$ & 14.2 & 14 \\
\hline $\begin{array}{l}\text { N: } 8 \text { layers of carbon fibers, each } 100 \mu \mathrm{m} \text { in thickness, and } \\
9 \text { layers of PA foils, each } 100 \mu \mathrm{m} .\end{array}$ & $1240 \pm 130$ & 10.5 & 14 \\
\hline
\end{tabular}

CFRP samples, which consisted of 5 layers of carbon fibers and 6 layers of PA films, had a mean tensile strength of $1001 \pm 142 \mathrm{MPa}$ and a density of $1259 \mathrm{~g} \cdot \mathrm{cm}^{-3}$, leading to a fiber content of approximately $19 \mathrm{vol} \%$. The maximum tensile strength was achieved with 8 layers of carbon fibers and 9 PA layers, all $100 \mu \mathrm{m}$ in thickness. In that case, the density of the CFRP was $1.336 \mathrm{~g} \cdot \mathrm{cm}^{-3}$. Consequently, the fiber content was approximately $33 \mathrm{vol} \%$ and the mean tensile strength was $1240 \pm 130 \mathrm{MPa}$.

\section{Discussion}

It has been shown that fiber reinforced plastic can be fabricated by ultrasonic welding of thermoplastic polymer films and both glass and carbon fibers. The process allows for the employment of various thermoplastic matrix materials such as PP, PE or PA. The maximum thickness of a CFRP achieved this way was $1.2 \mathrm{~mm}$. Thicker samples could not be manufactured because of the limited power of the ultrasonic welding machines available. The lateral dimensions of the samples are also a function of the available ultrasonic power because larger areas of the horn require more power for successful welding. The material palette is also limited by the power of the ultrasonic welding machine because thermoplastic polymers with a higher softening temperature such as polyether etherketone (PEEK) require more ultrasonic power for welding. The limited welding area could be extended by ultrasonic welding machines with rotating horns and anvils. However, the width of such horns up to now is limited to approximately $20 \mathrm{~mm}$. As a consequence, improved ultrasonic welding machines are desirable for the ultrasonic fabrication of fiber reinforced plastics.

Unidirectional fibers are squeezed out perpendicular to their direction by ultrasonic welding. Therefore, it was necessary to fix them at a significant tensile stress before welding. Employing canvas is a solution for this problem. On the other hand, using unidirectional fibers enables choosing the directions of maximum strength with more freedom. Thus further developments of the process are desirable, allowing for more designs of the samples. Besides this, the fiber content achievable by 
ultrasonic welding should be enhanced. The maximum fiber content obtained so far was $33 \mathrm{vol} \%$ yielding a tensile strength of $1.2 \mathrm{GPa}$. For high performance applications such as aviation or aerospace a fiber content of approximately $50 \mathrm{vol} \%$ and a tensile strength of up to $2 \mathrm{GPa}$ are usual [31] indicating that further improvements may also be possible for the fabrication by ultrasonic welding.

For several applications it is desirable to construct three-dimensional parts from FRP. The processes described here so far have been employed only for manufacturing flat FRP plates. Thus, further development work will also be necessary to allow for the fabrication of more complex geometries. Since there is a lot of freedom to arrange the fibers for ultrasonic welding, there appear to be chances for new designs.

The ultrasonic fabrication of CFRP processes dry carbon fibers and solid thermoplastic matrix material to semi-finished CFRP or CFRP products within seconds. Therefore, the fabrication process is much faster than state of the art fabrication of CFRP, e.g., by pultrusion or the processing of semi-finished CFRP products such as prepregs. Furthermore, all raw materials can be stored at room temperature for a nearly unlimited amount of time.

\section{Conclusions}

The fabrication of FRP by ultrasonic welding of polymer films and fibers is a promising new process enabling fast and low-cost fabrication. In contrast to other approaches in current research activities, the process presented within this paper does not require semi-finished FRP products as raw materials. It uses dry fibers and solid polymer film material, which can be purchased relatively cost-effectively by industrial suppliers. However, due to the early stage of the research, further development work is required to enhance fiber content and area and thickness of the products fabricated this way. As processing parameters are usually determined by trial and error, it seems possible to optimize the quality of the ultrasonically fabricated FRP through an intensively process parameter study. Besides the optimization of the process parameters, using a preliminary tension on the fibers during the fabrication process may avoid widening of the fiber rovings after the welding process, leading to an increase of both material thickness and tensile strength of the FRP.

Furthermore, the statistically significance of the measured tensile strength of the ultrasonically fabricated FRP needs to be determined by using statistical methods such as analysis of variance (ANOVA). To evaluate the quality of the FRP, values of tensile strength, which were measured in experiments, need to be compared to theoretical values predicted using composite theory.

Many issues such as the microscopical structure, the wrinkling of the fibers, the squeezing of the matrix materials or the porosity of the ultrasonically fabricated FRP were not investigated in this paper. However, these experiments and examinations could not be performed yet due to limited resources. Therefore, they need to be addressed in future works.

Author Contributions: Conceptualization, A.G. and W.K.S.; Methodology, A.G., W.Z., N.G.; W.K.S.; Writing-Original Draft Preparation, A.G.; Writing-Review \& Editing, W.K.S.; Supervision, J.S.; Project Administration, A.G.

Funding: This research received no external funding.

Conflicts of Interest: The authors declare no conflict of interest.

\section{References}

1. Neitzel, M.; Mitschang, P.; Breuer, U. Handbuch Verbundwerkstoffe-Werkstoffe, Verarbeitung, Anwendung, 2nd ed.; Carl Hanser: Munich, Germany, 2014; ISBN 978-3-446-43696-1.

2. Lengsfeld, H.; Wolff-Fabris, F.; Krämer, J.; Lacalle, J.; Altstädt, V. Faserverbundwerkstoffe-Prepregs und ihre Verarbeitung, 1st ed.; Carl Hanser: Munich, Germany, 2014; ISBN 978-3-446-43300-7.

3. Kraus, T.; Kühnel, M.; Witten, E. Composites-Marktbericht 2016-Markt-entwicklungen, Trends, Ausblicke und Herausforderungen, 1st ed.; Carbon Composites e.V.: Augsburg, Germany, 2016. 
4. Suzuki, T.; Takahashi, J. Prediction of Energy Intensity of Carbon Fibre Rein-forced Plastics for Mass-Produces Passenger Cars. In Proceedings of the 9th Japan Interna-Tional SAMPE Symposium, Tokyo, Japan, 25-28 April 2005.

5. Sackmann, J.; Burlage, K.; Gerhardy, C.; Memering, B.; Liao, S.; Schomburg, W.K. Review on ultrasonic fabrication of polymer micro devices. Ultrasonics 2015, 56, 189-200. [CrossRef] [PubMed]

6. Daniels, H.P.C. Ultrasonic Welding. Ultrasonics 1965, 3, 190-196. [CrossRef]

7. Palardy, G.; Villegas, I.R. On the effect of flat energy directors thickness on heat generation during ultrasonic welding of thermoplastic composites. Compos. Interfaces 2017, 24, 203-214. [CrossRef]

8. Villegas, I.R.; Moser, L.; Yousefpour, A.; Mitschang, P.; Bersee, H.E. Process and performance evaluation of ultrasonic, induction and resistance welding of advanced thermoplastic composites. J. Ther. Compos. Mater. 2012, 26, 1007-1024. [CrossRef]

9. Jongbloed, B.; Teuwen, J.; Palardy, G.; Villegas, I.F. Improving weld uniformity in continuous ultrasonic welding of thermoplastic composites. In Proceedings of the 18th European Conference on Composite Materials (ECCM18), Athens, Greece, 25-28 June 2018.

10. Gomer, A.; Sackmann, J.; Schomburg, W.K. Gefügige Kunststoffe. Kunststoffe 2016, 12, 73-75.

11. Tsiangou, E.; Teixeira de Freitas, S.; Villegas, I.F.; Benedictus, R. Ultrasonic welding of CF/Epoxy to CF/PEEK composites: Effect of the energy director material on the welding process. In Proceedings of the 18th European Conference on Composite Materials (ECCM18), Athens, Greece, 25-28 June 2018.

12. Voleppa, Q.; Pardoenb, T.; Baillya, C. Thermoset composite assembling method by welding of thermoplastic surface layers: Microstructure and toughness of the resulting thermoplastic/epoxiy resin interfaces. In Proceedings of the 16th European Conference on Composite Materials (ECCM16), Sevilla, Spain, 22-26 June 2016.

13. Rizzolo, R.H.; Walczyk, D.F. Ultrasonic consolidation of thermoplastic composite prepreg for automated fiber placement. J. Ther. Compos. Mater. 2016, 29, 1480-1497. [CrossRef]

14. Dell'Anna, R.; Lionetto, F.; Montagna, F.; Maffezzoli, A. Lay-Up and Consolidation of a Composite Pipe by In Situ UltrasonicWelding of a Thermoplastic Matrix Composite Tape. Materials 2018, 11, 786. [CrossRef] [PubMed]

15. Pasternak, M. Laminieren von Carbon-Preforms. Kunststoffe 2012, 10, 188-189.

16. Pasternak, M. Ultraschall als Energiequelle zum Laminieren von CFK-Schallwellen richten Carbonfasern aus. Plastverarbeiter. Available online: https://www.plastverarbeiter.de/38200/schallwellen-richtencarbonfasern-aus/ (accessed on 14 September 2018).

17. Khaled, Y.; Mehdi, H. Processing of thermoplastic matrix composites through automated fiber placement and tape laying methods. J. Ther. Compos. Mater. 2017, 1, 1-150. [CrossRef]

18. Chu, Q.; Li, Y.; Xiao, J.; Huan, D.; Zhang, X.; Chen, X. Processing and characterization of the thermoplastic composites manufactured by ultrasonic vibration-assisted automated fiber placement. J. Ther. Compos. Mater. 2018, 11, 339-358. [CrossRef]

19. Lionetto, F.; Dell'Anna, R.; Montagna, F.; Maffezzoli, A. Ultrasonic assisted consolidation of commingled thermoplastic/glass fibre rovings. Front. Mater. 2015, 2, 1-9. [CrossRef]

20. Lionetto, F.; Dell'Anna, R.; Montagna, F.; Maffezzoli, A. Modeling of continuous ultrasonic impregnation and consolidation of thermoplastic matrix composites. Compos. Part A Appl. Sci. Manuf. 2016, 82, 119-129. [CrossRef]

21. Technical Data Sheet Branson 2000IW+ Ultrasonic Welder. Available online: http://www.emerson.com/enus / catalog/branson-2000iw-ultrasonic-welder (accessed on 20 July 2018).

22. Technical Data Sheet HiQ DIALOG SpeedControl Ultrasonic Welding Machines. Available online: https: / www.herrmannultraschall.com/en/products/ultrasonic-welding-machines/weld-machines-hiqproduction-series/ (accessed on 20 July 2018).

23. Technical Data Sheet CERA 100 Ultrasonic Welding Machines. Available online: www.cera-groupecera. $\mathrm{com} / \mathrm{en} /$ standards/machines-to-weld-and-or-cut-by-sonics/cera-ultrasonic-ultrasonic-sewing (accessed on 20 July 2018).

24. Technical Data Sheet Zwicki Line Materials Testing Machines Z5.0 Tensile Testing Machine. Available online: https:/ / www.zwick.co.uk/universal-testing-machines/zwickiline (accessed on 20 July 2018).

25. Tecfilm PP TC 00170 Data Sheet; Dr. Dietrich Müller GmbH: Ahlhorn, Germany; Available online: www.mueller-ahlhorn.com/fileadmin/Downloads/PDF/PDFDateien/TC_00170_de.pdf (accessed on 14 September 2018). 
26. Nowocast HD Data Sheet; Nowofol Kunststoffprodukte GmbH \& Co. KG: Siegsdorf, Germany, 2018.

27. Cast Nylon Film PA 6 Data Sheet; Mf-Folien GmbH: Kempten, Germany, 2018.

28. Technical Data Sheet Tenax-HTS40 F13 12K 800tex Carbon Fiber Roving. Available online: https:/ / www. teijincarbon.com/de/produkte/tenax\%c2\%ae-kohlenstofffaser/tenax\%c2\%ae-filamentgarn/ (accessed on 20 July 2018).

29. E-CR1200 Data Sheet; Mühlmeier GmbH \& Co. KG: Bärnau, Gemany. Available online: https:/ / www.muehlmeier.de/fileadmin/user_upload/DE/composite/produktinformation/ muehlmeier_de_rovings_e-cr-glas_direktroving.pdf (accessed on 14 September 2018).

30. Technical Data Sheet KDL-8003 Carbon Fiber Canvas. Available online: https://www.carbon-vertrieb. com/shop/product_info.php?products_id=1319\&MODsid=jgjvpnod8p4jbnrjb34arkajtq1brhm2 (accessed on 20 July 2018).

31. Technical Data Sheet Celstran CFR-TP PPS CF-60-01_-PPS Carbon Fiber Tape. Available online: http: / / tools.celanese.com/standard/main/quicksearch/ds/0 (accessed on 20 July 2018).

(C) 2018 by the authors. Licensee MDPI, Basel, Switzerland. This article is an open access article distributed under the terms and conditions of the Creative Commons Attribution (CC BY) license (http:/ / creativecommons.org/licenses/by/4.0/). 